\title{
The Mechanism of Intragranular Acicular Ferrite Nucleation Induced by Mg-Al-O Inclusions
}

\author{
Kong Hui, Zhou YaHui, Lin Hao, Xia Yunjin, Li Jie, Yue Qiang, and Cai ZhengYu \\ School of Metallurgical Engineering, Anhui University of Technology, Maanshan, Anhui 243002, China \\ Correspondence should be addressed to Cai ZhengYu; zhengyucai_ahut@163.com
}

Received 6 May 2014; Accepted 12 January 2015

Academic Editor: Pavel Lejcek

Copyright ( 2015 Kong Hui et al. This is an open access article distributed under the Creative Commons Attribution License, which permits unrestricted use, distribution, and reproduction in any medium, provided the original work is properly cited.

\begin{abstract}
The features of inclusion and microstructure for carbon structural steel containing $\mathrm{Mg}$-Al-O inclusions were studied through the scanning electron microscope (SEM) and Energy Dispersive Spectrometer (EDS). It can be seen that, in Mg-Al-O inclusions, the elements of $\mathrm{Mn}, \mathrm{Si}$, and $\mathrm{S}$ coexist, and their central mole ratio of $\mathrm{Mg} / \mathrm{Al}$ varies in a wide range. This value for most inclusions is larger than 0.5, which suggests the formation of solid solution between $\mathrm{MgAl}_{2} \mathrm{O}_{4}$ and $\mathrm{MgO}$. After etching, the typical microstructure of intragranular acicular ferrites is observed, which is due to the nucleation effect induced by Mg-Al-O inclusions. From the SEMEDS mapping images, it is found that the element of sulfur accumulates on the periphery of nucleation inclusion. Moreover, line EDS analysis hints that Mn-depletion zone (MDZ) exists in steel matrix, which is adjacent to the complex inclusion. Combined with the theoretical analysis, this phenomenon can be explained by the absorption of $\mathrm{Mn}$ due to the magnesium vacancy in $\mathrm{MgAl}_{2} \mathrm{O}_{4}$, and this MDZ promotes the nucleation of intragranular acicular ferrite. Through statistical analysis of SEM images for microstructure, the probabilistic nature of inducing nucleation effect is revealed. These results may be helpful to clarify the nature of oxide metallurgy.
\end{abstract}

\section{Introduction}

Nonmetallic oxides have been considered being harmful to the ductility, toughness, and fatigability of steel because of their high melting point and hardness [1]. However, in 1990, the technology of oxide metallurgy was proposed to utilize the positive effect of the fine oxide to refine the grain [2-4]. Due to the perspective prospect, this technology has been a subject of intense study.

Among different kinds of nonmetallic inclusions [5-7], which have been utilized in oxide metallurgy, Mg-bearing oxide has recently attracted much attention due to its special properties [8]. It can not only inhibit austenitic grain growth through the pinning effect $[8,9]$ but also induce nucleation of intragranular acicular ferrite (IAF) during the austeniteferrite transformation [10]. The former is based on the fact that Mg-bearing oxides are thermally stable second phase particles that do not easily dissolve or grow at a temperature as high as $1673 \mathrm{~K}$ [8]. However, the mechanism of the latter is still under discussion.
In 2011, Wen et al. [10] pointed out that the lattice disregistry is the possible mechanism to explain the inducing nucleation effect of $\mathrm{Mg}$-bearing oxides. First, they simplify the Mg-bearing oxides as $\mathrm{MgAl}_{2} \mathrm{O}_{4}$ and $\mathrm{MgO}$. Then through calculations, they find that the lattice disregistry between $\mathrm{MgAl}_{2} \mathrm{O}_{4}$ and $\alpha$-Fe is only $0.6 \%$, and the value between $\mathrm{MgO}$ and $\alpha$-Fe is only $4.03 \%$. According to the Bramfitt's theory [6], if the lattice disregistry is less than $6 \%$, the heterogeneous nucleation will be well induced. But this explanation is not consistent with the complexity of inclusion's feature. On the one hand, other elements, such as $\mathrm{Mn}, \mathrm{S}$, and $\mathrm{Si}$, coexist with $\mathrm{Mg}-\mathrm{Al}-\mathrm{O}$ in inclusion, which leads to the inaccuracy in only considering pure $\mathrm{MgAl}_{2} \mathrm{O}_{4}$. On the other hand, according to the PCPDFWIN Database of JCPDS (version 1.1.1.0, 2002), the finely crystal structure types of Mg-Al-O, Mg-Al-Mn-O, and $\mathrm{Mg}-\mathrm{Al}-\mathrm{Si}-\mathrm{O}$ are 62, 9, and 84, respectively. This makes it difficult to confirm the exact structural parameters of $\mathrm{Mg}$ bearing oxides, let alone the parameters at the transformation temperature between austenite and ferrite. In fact, Chai et al. [11] have clearly pointed out that $\mathrm{MgO}$ is impotent to induce 

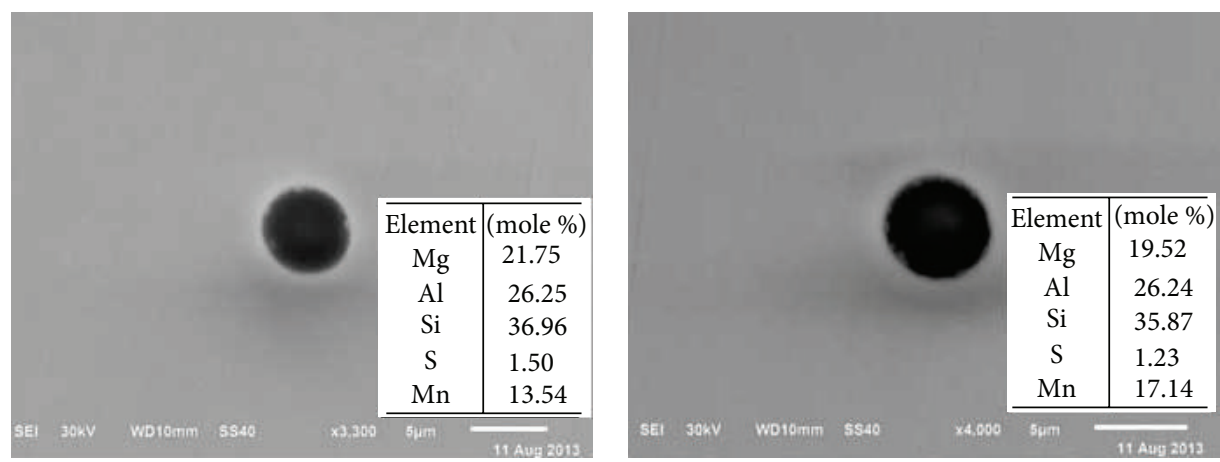

FIGURE 1: SEM micrographs and EDS results for typical magnesia-bearing oxide.

the IAF nucleation. Thus, the mechanism of IAF nucleation induced by $\mathrm{Mg}$-Al oxides should be further clarified.

In recent years, different experimental tools have been applied to study the nature of oxide metallurgy, such as transmission electron microscope (TEM) [12], scanning Auger microprobe (SAM) [13], and scanning electron microscope (SEM) [14]. Among them, the role of Energy Dispersive Spectrometer (EDS), which is equipped on SEM, is special. On the one hand, due to its limitation in accuracy, EDS can only qualitatively describe the composition of submicrometer scale. On the other hand, compared with other more precise tools, EDS can be easily utilized to analyze a large number of inclusions and characterize their statistical features. Moreover, line and mapping functions of EDS can further qualitatively describe the distribution of elements in inclusion. These results are helpful to gain more insight into the inclusion's inducing nucleation effect for IAF. Till now, the application of these tools to $\mathrm{Mg}-\mathrm{Al}-\mathrm{O}$ inclusions is still lacking. Thus, the objective of this paper is to elucidate mechanism of IAF nucleation induced by $\mathrm{Mg}-\mathrm{Al}-\mathrm{O}$ inclusions through systemic measurements by SEM and EDS.

\section{Experimental Procedure}

The experiment is carried out in a high-heat tube-type resistance furnace (KSY-10-18). The commercial $20 \mathrm{MnSi}$ (about $1000 \mathrm{~g}$ ) were charged into an alumina crucible. After preheating, the charged alumina crucible was lowered into the hot zone of resistance furnace with a graphite outer crucible. The furnace temperature was maintained at $1873 \mathrm{~K}$. When melting was done, the appropriate amounts of aluminum and magnesia alloy (Mg: 8\%, mass percentage) were added into the molten steel in turn. After being held for 20 minutes at $1873 \mathrm{~K}$, the crucible was taken out. After solidification, the sample is quenched into water.

The contents of magnesia and acid-soluble aluminum (Sol.Al) were analyzed by the Inductively Coupled Plasma Spectroscopy method. The sample composition is shown in Table 1. The morphology and composition of inclusions were characterized by the SEM (JSM-6510LV) and EDS (INCA Feature X-Max 20). To conduct further detailed analysis of inclusions, the line and mapping functions of EDS are applied to reveal the elements distribution in inclusion. The sample
TABLE 1: Chemical composition of steel sample (mass percentage).

\begin{tabular}{cccccccc}
\hline & $\mathrm{C}$ & $\mathrm{Si}$ & $\mathrm{Mn}$ & $\mathrm{P}$ & $\mathrm{S}$ & $\mathrm{Sol} . \mathrm{Al}$ & $\mathrm{Mg}$ \\
\hline Mass Pct & 0.13 & 0.36 & 0.95 & 0.021 & 0.019 & 0.0013 & 0.0008 \\
\hline
\end{tabular}

was polished carefully and etched in $3 \mathrm{Vol} \%$ Nital solution for microstructure observation, which was performed by the optical and scanning electron microscopes.

\section{Results and Discussion}

To characterize the nature of inclusion, $100 \mathrm{Mg}$-bearing inclusions are randomly selected and analyzed with SEMEDS. Figure 1 presents two typical SEM images and their composition. It should be mentioned that the data processing for EDS is carried out in two steps [15]. First, elements of iron and oxygen are excluded from the composition analysis. Iron was excluded to eliminate the contribution of signals from the steel matrix, and oxygen was ruled out since oxygen accuracy is not sufficient for scientific analysis. Second, the content of the remaining elements was normalized to $100 \%$ and reported in the unit of atomic percent. In fact, similar data processing is also carried out by Zhuo et al. [15].

Through the statistical analysis of SEM-EDS images, three features of Mg-bearing inclusions can be educed. First, the elements of magnesia and alumina coexist in inclusion, and no pure $\mathrm{MgO}$ are found. This is consistent with earlier reports. For example [16], Luo et al. pointed out that even 2 ppm Mg addition resulted in the oxide formation change from $\mathrm{Al}_{2} \mathrm{O}_{3}$ to $\mathrm{MgAl}_{2} \mathrm{O}_{5}$. Second, in $\mathrm{Mg}-\mathrm{Al}-\mathrm{O}$ inclusions, other elements, such as $\mathrm{Si}, \mathrm{Mn}$, and $\mathrm{S}$, are also found. This coexistence means that the simplification of $\mathrm{MgO}$ and $\mathrm{MgAl}_{2} \mathrm{O}_{5}$ is not precise. Third, the mole ratio of $\mathrm{Mg} / \mathrm{Al}$ is not exactly equal to the ideal value ( 0.5 for $\mathrm{MgAl}_{2} \mathrm{O}_{5}$ ) and varies in a wide range. To characterize this distribution, each central mole ratio of $\mathrm{Mg} / \mathrm{Al}$ for $100 \mathrm{Mg}-\mathrm{Al}-\mathrm{O}$ inclusions is analyzed through the EDS spot function. The distribution of mole ratio $(\mathrm{Mg} / \mathrm{Al})$ is shown in Figure 2. It is found that the ratio for most inclusions is larger than 0.5 , which hints the formation of solid solution between $\mathrm{MgAl}_{2} \mathrm{O}_{4}$ and $\mathrm{MgO}$. These features mean the complexity of $\mathrm{Mg}-\mathrm{Al}-\mathrm{O}$ inclusions, which should be considered to explain its inducing nucleation effects. 


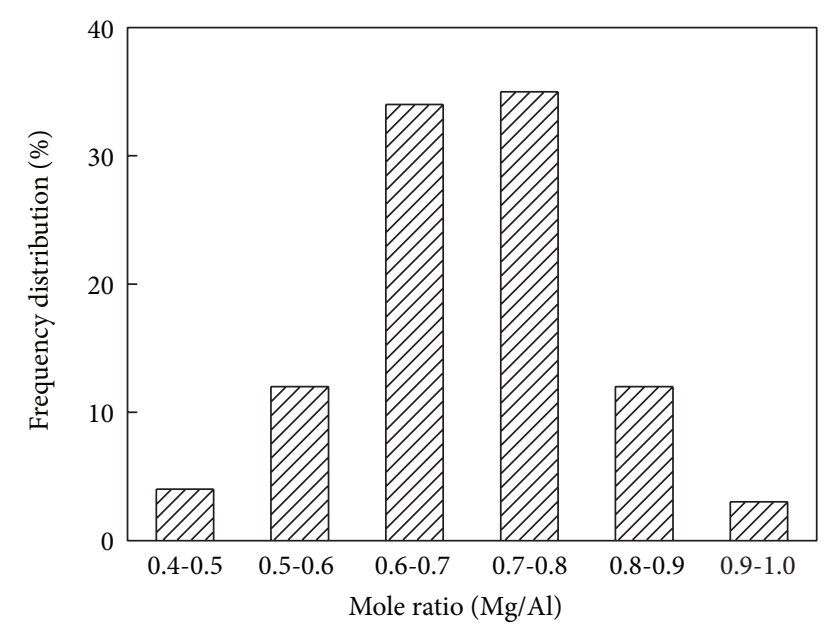

FIgURE 2: The distribution of central mole ratio $(\mathrm{Mg} / \mathrm{Al})$ for magnesia-bearing oxides.

Figure 3 describes the sample's optical microstructure after etching in $3 \mathrm{Vol} \%$ Nital solution. It can be seen that the intragranular acicular ferrites are distributed among the prior austenite grain boundaries, and these IAF plates seem to be formed independently at large angles. This results in an interlocking appearance, which is similar to the typical microstructure with IAF in Ti-contained steel $[17,18]$. Figure 3 clearly shows that these IAF plates initiate from a dark spot, which hints that an inclusion induces the IAF nucleation. Since optical microscope does not have the function of composition analysis, the sample's etched microstructure is further characterized by SEM and EDS.

From Figure 4(a), it is found that seven laths emanate from a single $\mathrm{Mg}-\mathrm{Al}-\mathrm{O}$ inclusion, which confirms that the inclusion induces the formation of intragranular acicular ferrites. This nucleation effect is similar to that of typical Ti-O [17, 18]. Moreover, from the element mapping figures (Figures 4(b) 4(f)), it can be seen that the element of sulfur congregates at the inclusions margin. This phenomenon is also confirmed by Luo et al. [16]. They found that $\mathrm{MnS}$ can heterogeneously nucleate on $\mathrm{MgAl}_{2} \mathrm{O}_{5}$ at $1523 \mathrm{~K}$ and suggested that $2 \mathrm{ppm} \mathrm{Mg}$ addition resulted in the inclusion formation change from $\mathrm{MnS}-\mathrm{Al}_{2} \mathrm{O}_{3}$ to $\mathrm{MnS}-\mathrm{MgAl}_{2} \mathrm{O}_{5}$. Since element of manganese exists in entire inclusion, only the congregation of sulfur at inclusions margin is found.

According to Wen et al's paper [10], the lattice disregistry theory has been proposed to explain the mechanism of IAF nucleation induced by $\mathrm{Mg}-\mathrm{Al}-\mathrm{O}$ inclusions. However, this explanation is challenged by the following four facts. First, other elements, such as Mn, S, and Si, coexist with Mg-Al-O in inclusion. Second, according to the PCPDFWIN Database of JCPDS (version 1.1.1.0, 2002), the finely crystal structure types of Mg-Al-O, Mg-Al-Mn-O, and Mg-Al-Si-O are 62, 9, and 84 , respectively. This makes it difficult to confirm the exact structural parameters of Mg-bearing oxides, let alone the parameters at the transformation temperature between austenite and ferrite. Third, our statistical analysis shows that the mole ratio of $\mathrm{Mg} / \mathrm{Al}$ is not exactly equal to the ideal value
(0.5 for $\mathrm{MgAl}_{2} \mathrm{O}_{5}$ ) and varies in a wide range, which hints the formation of solid solution. Fourth, MnS heterogeneously nucleates on $\mathrm{MgAl}_{2} \mathrm{O}_{5}$ at the inclusion margin, which means the complexity of crystal structure at the interface between Mg-bearing inclusions and the IAF plates. Thus, this inducing effect cannot be explained only based on the lattice disregistry between $\mathrm{MgAl}_{2} \mathrm{O}_{4}$ and $\alpha$-Fe. Other alternative explanations should be considered.

In fact, the manganese-depleted zone (MDZ) mechanism has been widely accepted to explain the function of inclusions on nucleation effect of IAF $[13,14,19,20]$. The typical example is $\mathrm{Ti}_{2} \mathrm{O}_{3}$. This hypothesis is based on two assumptions. First, the cation vacancies exist in Ti-contained inclusions. Second, the effective ionic radius of $\mathrm{Mn}$ (six-coordinated $\mathrm{Mn}^{3+}: 0.0645 \mathrm{~nm}$ for high-spin state) is similar to that of $\mathrm{Ti}$ (six-coordinated $\mathrm{Ti}^{3+}: 0.067 \mathrm{~nm}$ ) [21]. Thus, Ti-contained inclusions can absorb neighboring $\mathrm{Mn}$ atoms from the $\mathrm{Fe}$ matrix, which results in a manganese-depleted zone in $\mathrm{Fe}$ matrix adjacent to inclusion. Since $\mathrm{Mn}$ is one of austenite stabilizing elements, this MDZ will lower the stability of austenite and promote the nucleation of ferrites. This leads to the nucleation of IAF.

In Mg-Al-O inclusions, the upper two conditions are also met. On the one hand, magnesium vacancy is one of the intrinsic defects in $\mathrm{MgAl}_{2} \mathrm{O}_{4}$ through a computer simulation study by using empirical potential parameters [22]. On the other hand, the effective ionic radius of $\mathrm{Mg}$ (four-coordinated $\mathrm{Mg}^{2+}: 0.057 \mathrm{~nm}$ ) is similar to that of $\mathrm{Mn}$ (four-coordinated $\mathrm{Mn}^{2+}: 0.066 \mathrm{~nm}$ for high-spin state) [21]. It should be mentioned that the effective ionic radius is closely related to coordination number, valence state, and spin state. The selection of coordination number is according to the crystal structure, the valence state is dependent on that of substitution ions, and the spin state is closely related to arrangement of the outermost electrons. For example, the coordination number of $\mathrm{Ti}^{3+}$ in $\mathrm{Ti}_{2} \mathrm{O}_{3}$ is 6 , while that of $\mathrm{Mg}^{2+}$ in $\mathrm{MgAl}_{2} \mathrm{O}_{4}$ is 4 . As for $\mathrm{Mn}$, the values of effective ionic radius are listed according to the corresponding coordination number and valence state.

Based on upper two sides, a conclusion may be drawn that the absorption of $\mathrm{Mn}$ by $\mathrm{MgAl}_{2} \mathrm{O}_{4}$ is feasible and reasonable. In fact, the $\mathrm{Mn}$-doping on the $\mathrm{Mg}$ site in $\mathrm{MgAl}_{2} \mathrm{O}_{4}$ is well studied by materials scientists, and the doping concentration is high up to $50 \%$, such as $\mathrm{Mg}_{0.5} \mathrm{Mn}_{0.5} \mathrm{Al}_{2} \mathrm{O}_{4}$ [23]. They systematically studied this doping effect and applied this kind of doping material in optical devices [24]. According to the distribution of mole ratio $(\mathrm{Mg} / \mathrm{Al})$ shown in Figure 2, it can be seen that, in our sample, most $\mathrm{Mg}$-bearing inclusions are the solid solution between $\mathrm{MgAl}_{2} \mathrm{O}_{4}$ and $\mathrm{MgO}$. Thus, these $\mathrm{Mg}$-bearing inclusions can also produce MDZ in steel matrix around them.

To verify the existence of MDZ, the line EDS analysis was applied to the inclusion, which induces the formation of intragranular acicular ferrites. These results are shown in Figures 5(a) and 5(b). Due to the limitation of accuracy, the line, which represents the content of $\mathrm{Mn}$, is not smooth and continuous. However, it can be clearly seen that the content of $\mathrm{Mn}$ shows a valley in steel matrix, which is adjacent to 

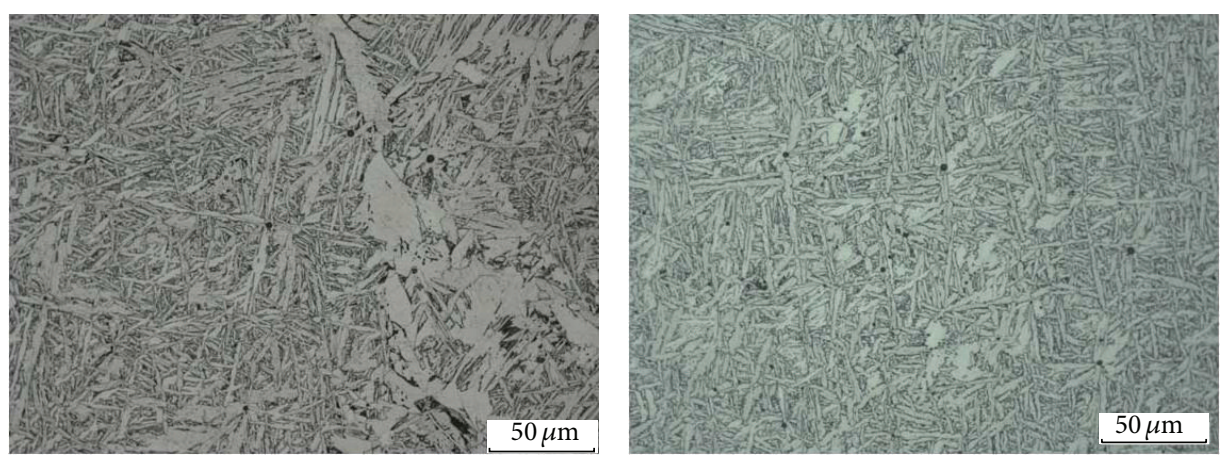

FIgURE 3: The sample's optical microstructure.

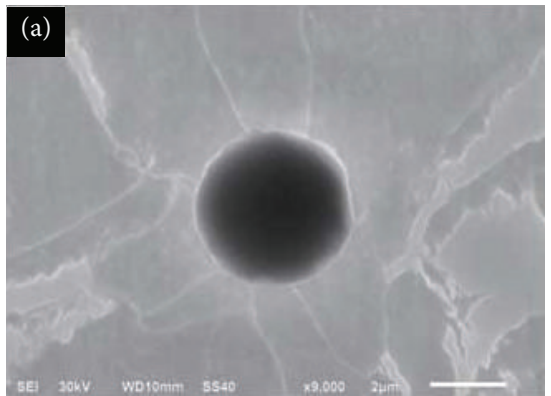

S
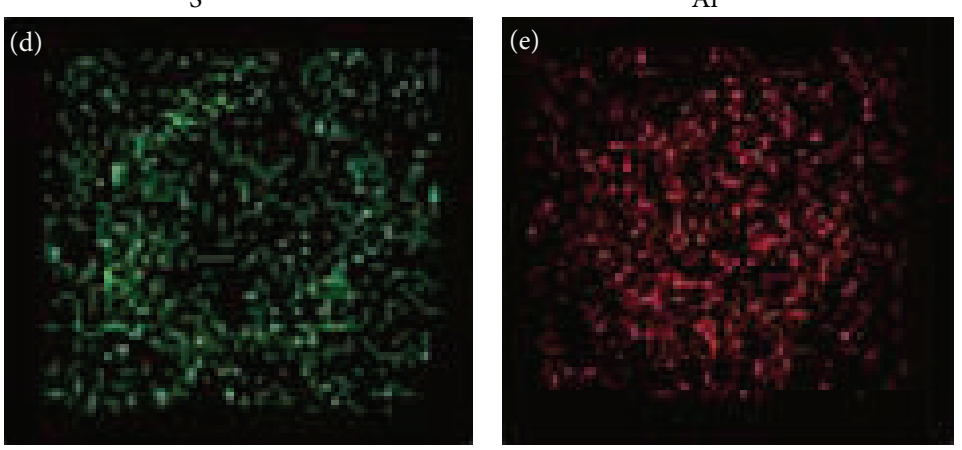

$\mathrm{Si}$

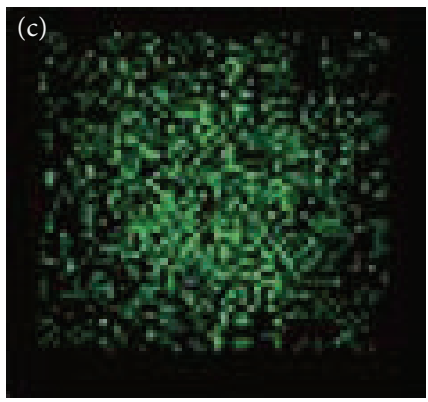

$\mathrm{Mn}$

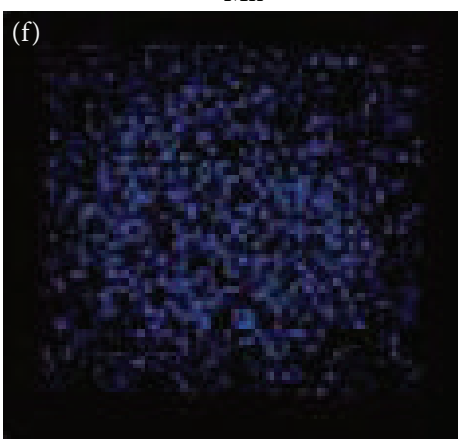

Figure 4: SEM micrograph (a) and EDS mapping images of various elements ((b): Mg; (c): Si; (d): S; (e): Al; (f): Mn) for the inclusion in etched sample.
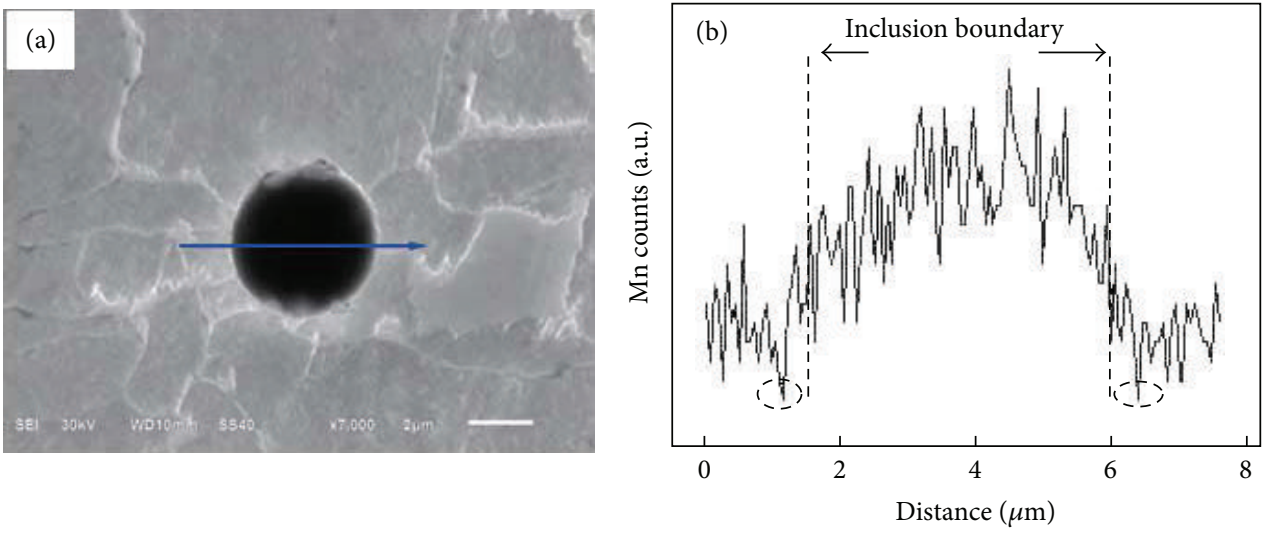

FIGURE 5: (a) The SEM image of inclusion, which induces the formation of intragranular acicular ferrites. (b) Line EDS analysis of Mn along the nucleation site of inclusion and surrounding steel matrix. 

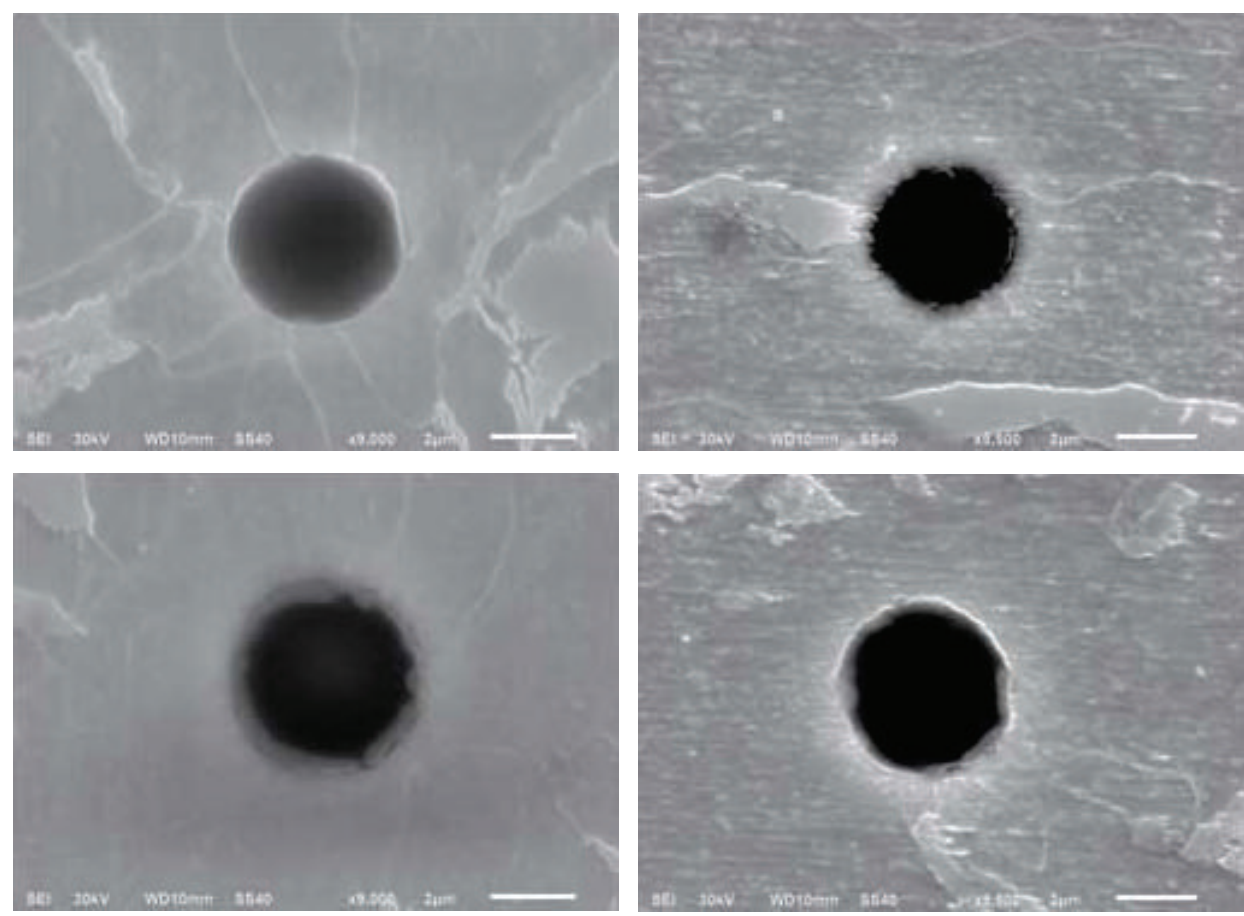

FIGURE 6: The diversity of nucleation effect induced by four typical Mg-Al-O inclusions.

the inclusion. The distance from minimum of Mn content to the interface of inclusion is about $0.4 \mu \mathrm{m}$. This observation and distance value are consistent with earlier reports in $\mathrm{Ti}$ contained oxides, such as about $0.6 \mu \mathrm{m}$ through the line EDS analysis [14] and $0.2 \mu \mathrm{m}$ through SAM [13]. In both papers, this observation is suggested to confirm the existence of MDZ. Thus, our results qualitatively hint the existence of MDZ. Though this evidence is not decisive, it is still helpful to settle this important issue.

Through statistical analysis of SEM images for microstructure, another important feature of inducing nucleation should be mentioned. That is probabilistic nature. In Figure 6, four typical $\mathrm{Mg}-\mathrm{Al}-\mathrm{O}$ inclusions are present, which are all found among the prior austenite grain boundaries. Their sizes are $4.2,3.6,4.4$, and $4.2 \mu \mathrm{m}$, respectively. The corresponding mole ratios of $\mathrm{Mg} / \mathrm{Al}$ are $0.72,0.70,0.64$, and 0.65 . However, similar size and ratio lead to totally different nucleation effect. This contrast hints that the study on the mechanism of oxide metallurgy cannot only focus on precise analysis on single inclusion. The statistical analysis should be carried out to clarify its probabilistic nature, and the concept of probability should be introduced to scientifically characterize relationship between the oxide features and effect of inducing nucleation. This needs great amount of work, which we will do in the future.

\section{Conclusion}

The features of inclusion and microstructure for Mg-treated carbon structural steel were studied through the SEM and EDS. It can be seen that, in magnesia-alumina oxides, central mole ratio of $\mathrm{Mg} / \mathrm{Al}$ is not fixed to the ideal value ( 0.5 for $\mathrm{MgAl}_{2} \mathrm{O}_{5}$ ) and varies in a wide range. Since this value for most inclusions is larger than 0.5, this hints the formation of solid solution between $\mathrm{MgAl}_{2} \mathrm{O}_{4}$ and $\mathrm{MgO}$. After etching, it is found that the magnesia-alumina inclusion can act as nucleation sites for acicular ferrite. Line EDS analysis suggests that the content of Mn shows a valley in steel matrix, which is adjacent to the inclusion. Combined with the theoretical analysis, this phenomenon can be explained by the absorption of $\mathrm{Mn}$ due to the magnesium vacancy in $\mathrm{MgAl}_{2} \mathrm{O}_{4}$, and this manganese-depleted zone plays an important role in the acicular ferrite formation. Furthermore, through statistical analysis of SEM images for microstructure, the probabilistic nature of inducing nucleation effect is revealed.

\section{Conflict of Interests}

The authors declare that there is no conflict of interests regarding the publication of this paper.

\section{Acknowledgments}

This work was supported by the National Natural Science Foundation of China (no. 51304001 and no. 51474001), Ministry of Education Science and Technology Research Key Project (211074), Ministry of Housing and Urban-Rural Development Research Project (2012-K4-41), Opening Fund of State Key Laboratory of Advanced Metallurgy (no. KF1307), and Anhui University of Technology Graduate Innovation Research (no. 2014137). 


\section{References}

[1] T. Gladman, "Developments in inclusions control and their effects on steel properties," Ironmaking and Steelmaking, vol. 19, no. 6 , pp. 457-463, 1992.

[2] J. Takamura and S. Mizoguchi, "Roles of oxides in steel performance," in Proceedings of the 6th International Iron and Steel Congress, vol. 1, pp. 591-597, Nagoya, Japan, 1990.

[3] P. A. Manohar, M. Ferry, and T. Chandra, "Five decades of the zener equation," ISIJ International, vol. 38, no. 9, pp. 913-924, 1998.

[4] B. Wen, B. Song, N. Pan, Q.-Y. Hu, and J.-H. Mao, "Effect of austenitizing temperature on microstructure in $16 \mathrm{Mn}$ steel treated by cerium," International Journal of Minerals, Metallurgy and Materials, vol. 18, no. 6, pp. 652-658, 2011.

[5] J.-H. Shim, Y. W. Cho, S. H. Chung, J.-D. Shim, and D. N. Lee, "Nucleation of intragranular ferrite at $\mathrm{Ti}_{2} \mathrm{O}_{3}$ particle in low carbon steel," Acta Materialia, vol. 47, no. 9, pp. 2751-2760, 1999.

[6] B. L. Bramfitt, "The effect of carbide and nitride additions on the heterogeneous nucleation behavior of liquid iron," Metallurgical Transactions, vol. 1, no. 7, pp. 1987-1995, 1970.

[7] I. Madariaga and I. Gutiérrez, "Role of the particle-matrix interface on the nucleation of acicular ferrite in a medium carbon microalloyed steel," Acta Materialia, vol. 47, no. 3, pp. 951-960, 1999.

[8] A. Kojima, A. Kiyose, R. Uemori et al., "Super high HAZ toughness technology with fine microstructure imparted by fine particles," Nippon Steel Technical Report, no. 90, pp. 2-6, 2004.

[9] K. Zhu and Z.-G. Yang, "Effect of Mg addition on the ferrite grain boundaries misorientation in HAZ of low carbon steels," Journal of Materials Science \& Technology, vol. 27, no. 3, pp. 252256, 2011.

[10] B. Wen, B. Song, N. Pan, Q. Y. Hu, and J. H. Mao, "Effect of SiMg alloy on inclusions and microstructures of $16 \mathrm{Mn}$ steel," Ironmaking and Steelmaking, vol. 38, no. 8, pp. 577-583, 2011.

[11] F. Chai, C.-F. Yang, H. Su, Y.-Q. Zhang, and Z. Xu, "Effect of magnesium on inclusion formation in Ti-killed steels and microstructural evolution in welding induced coarse-grained heat affected zone," Journal of Iron and Steel Research International, vol. 16, no. 1, pp. 69-74, 2009.

[12] J.-H. Qi, Z.-L. Xue, J. Wu, C.-G. Cheng, and Y.-M. Gao, “Tideoxidized products and formation mechanism of intragranular ferrite in high grade pipeline steels," Journal of Iron and Steel Research International, vol. 17, no. 7, pp. 63-67, 2010.

[13] C. C. Zheng, X. M. Wang, S. R. Li, C. J. Shang, and X. L. $\mathrm{He}$, "Effects of inclusions on microstructure and properties of heat-affected-zone for low-carbon steels," Science ChinaTechnological Sciences, vol. 42, pp. 662-671, 2012.

[14] X. Deng, M. Jiang, and X. Wang, "Mechanisms of inclusion evolution and intra-granular acicular ferrite formation in steels containing rare earth elements," Acta Metallurgica Sinica, vol. 25, no. 3, pp. 241-248, 2012.

[15] X.-J. Zhuo, Y.-Q. Wang, X.-H. Wang, and L. Hae-geon, “Thermodynamic calculation and MnS solubility of Mn-Ti oxide formation in Si-Mn-Ti deoxidized steel," Journal of Iron and Steel Research International, vol. 17, no. 2, pp. 10-16, 2010.

[16] S.-J. Luo, Y.-H. F. Su, M.-J. Lu, and J.-C. Kuo, "EBSD analysis of magnesium addition on inclusion formation in SS400 structural steel," Materials Characterization, vol. 82, pp. 103-112, 2013.

[17] H. Kong, S. Shao, Y. F. Shen et al., "Effect of aluminum on the nucleation of intragranular ferrite in Ti-added carbon structural steel," High Temperature Materials and Processes, vol. 32, no. 3, pp. 323-329, 2013.

[18] J.-S. Byun, J.-H. Shim, and Y. W. Cho, "Influence of Mn on microstructural evolution in Ti-killed C-Mn steel," Scripta Materialia, vol. 48, no. 4, pp. 449-454, 2003.

[19] J.-H. Shim, Y.-J. Oh, J.-Y. Suh et al., "Ferrite nucleation potency of non-metallic inclusions in medium carbon steels," Acta Materialia, vol. 49, no. 12, pp. 2115-2122, 2001.

[20] J.-S. Byun, J.-H. Shim, Y. W. Cho, and D. N. Lee, "Non-metallic inclusion and intragranular nucleation of ferrite in Ti-killed CMn steel," Acta Materialia, vol. 51, no. 6, pp. 1593-1606, 2003.

[21] R. D. Shannon, "Revised effective ionic radii and systematic studies of interatomic distances in halides and chalcogenides," Acta Crystallographica A, vol. 32, part 5, pp. 751-767, 1976.

[22] F.-W. Zhang, Q.-R. Zhang, T.-Y. Liu, Y.-Y. Sun, K. Tao, and J. Gale, "Computer simulation of intrinsic defects in $\mathrm{MgAl}_{2} \mathrm{O}_{4}$ ", Journal of University of Shanghai for Science and Technology, vol. 27, no. 2, pp. 104-106, 2005.

[23] M.-L. Li, Theoretical study on properties of magnesium aluminates spinel materials [Ph.D. thesis], Northeastern University, 2009.

[24] K. Izumi, S. Miyazaki, S. Yoshida, T. Mizokawa, and E. Hanamura, "Optical properties of $3 \mathrm{~d}$ transition-metal-doped $\mathrm{MgAl}_{2} \mathrm{O}_{4}$ spinels," Physical Review B-Condensed Matter and Materials Physics, vol. 76, no. 7, Article ID 075111, 2007. 

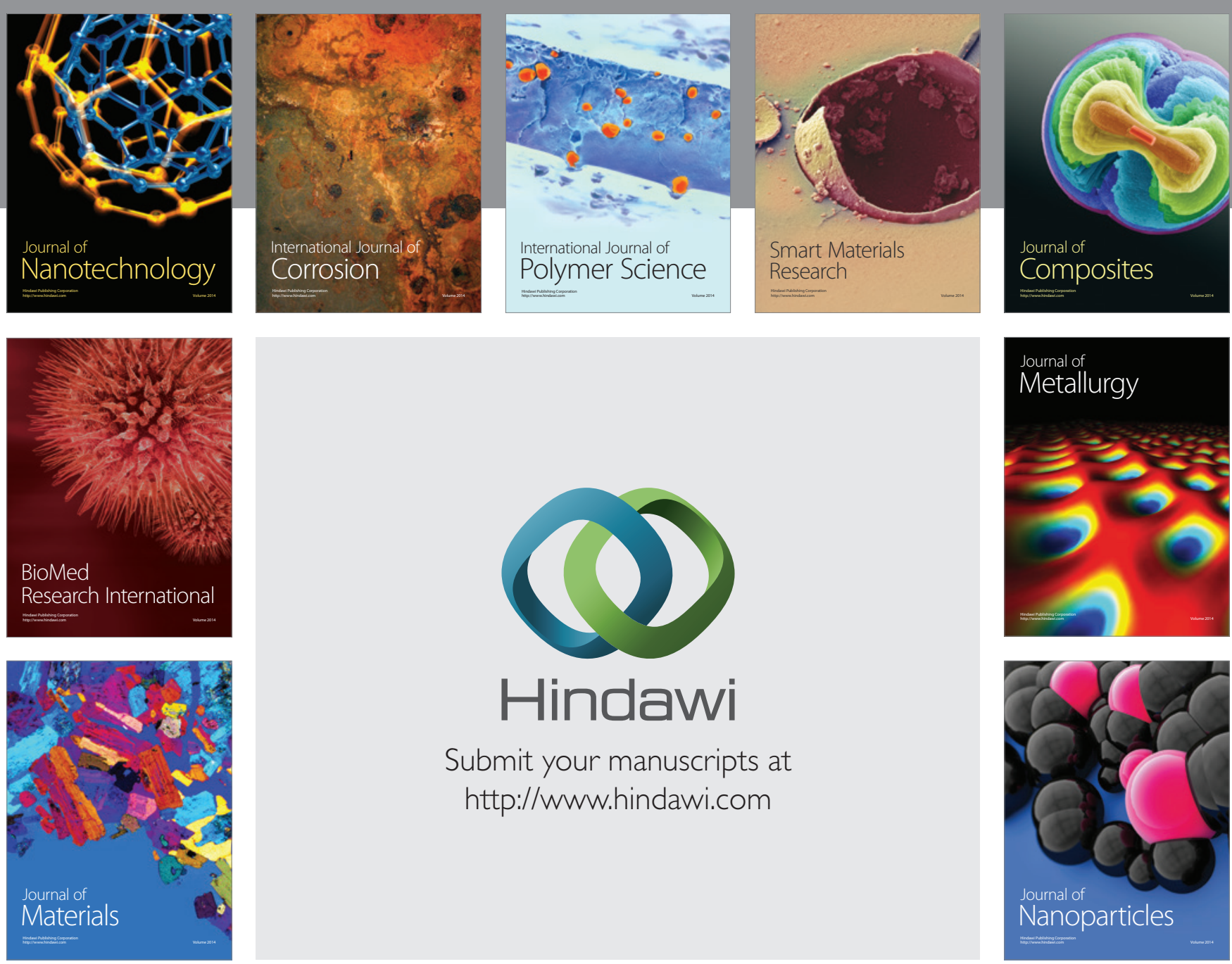

Submit your manuscripts at http://www.hindawi.com
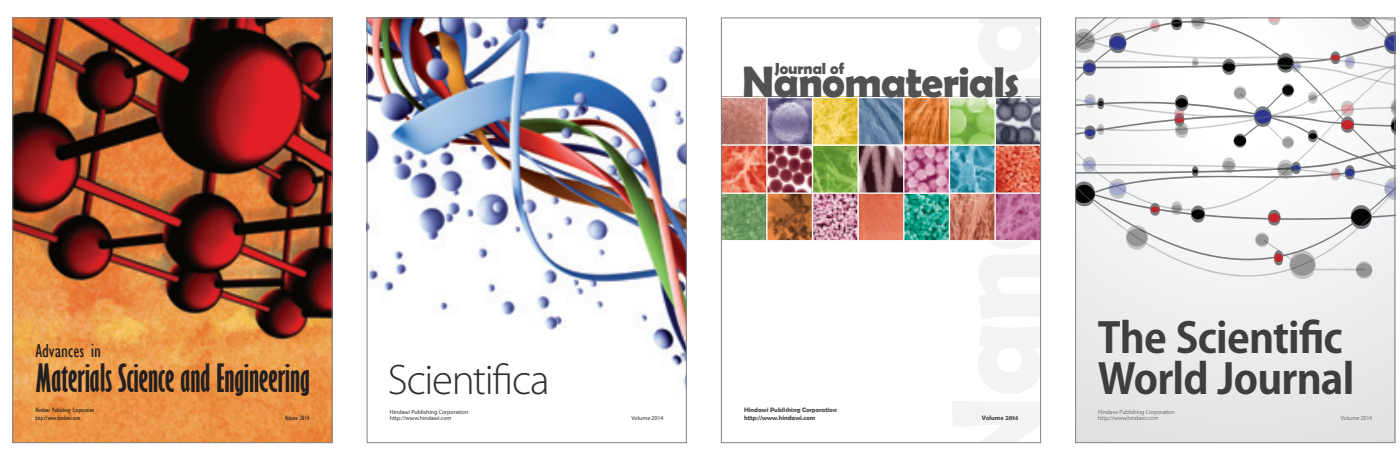

\section{The Scientific World Journal}
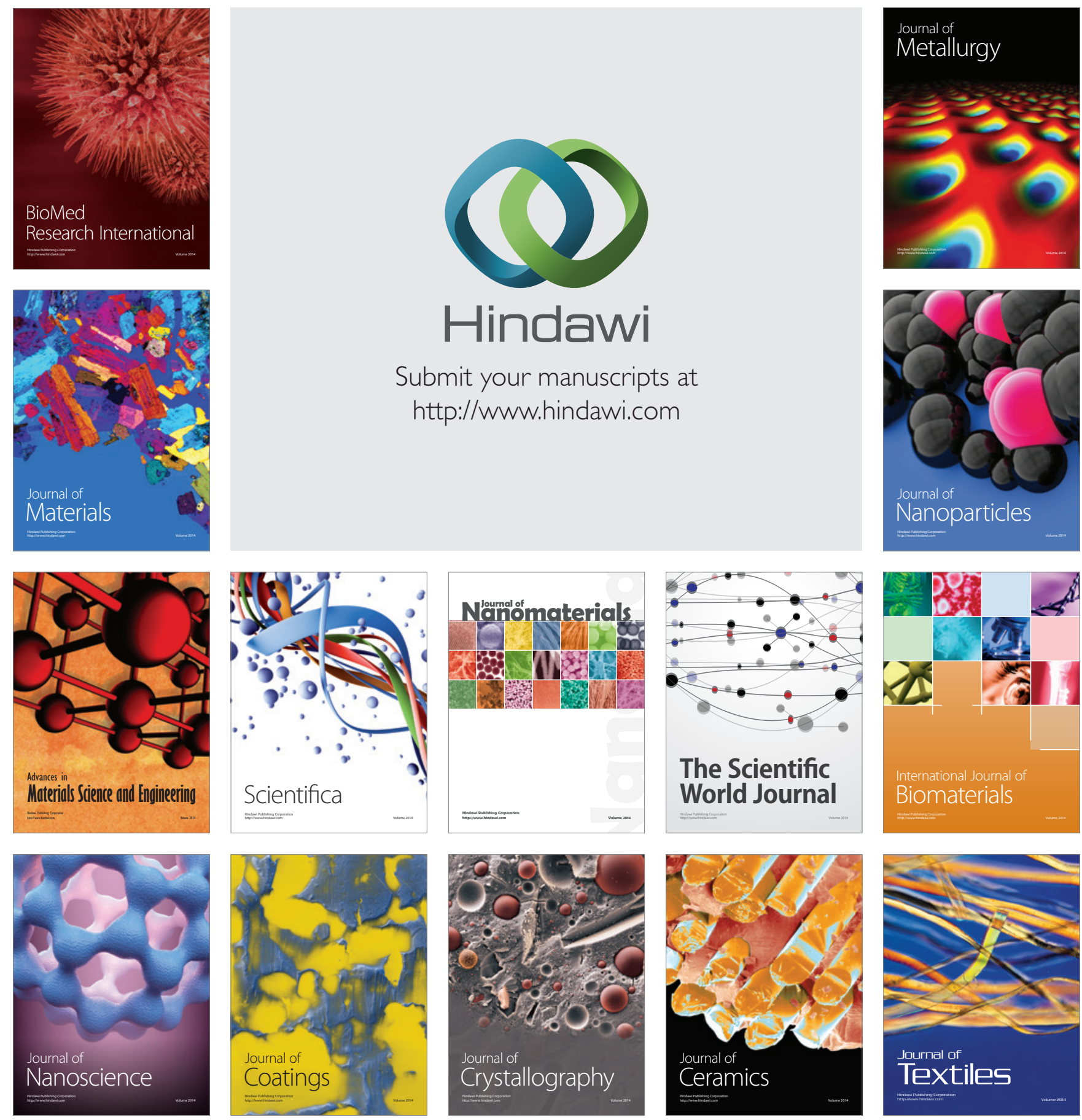